\title{
Characterization of Mechanical Properties of Aligned Date Palm Frond Fiber-Reinforced Low Density Polyethylene
}

\author{
K.I. Alzebdeh",a, M. M. Nassarb, M.A. Al-Hadhramia, O. Al-Aamria, S. Al-Defaaia and S. Al-Shuailya \\ a Department of Mechanical and Industrial Engineering, College of Engineering, Sultan Qaboos University, Oman. \\ b Palestine Polytechnic University, Hebron, State of Palestine.
}

Received 10 March 2017; Accepted 15 August 2017

\begin{abstract}
In recent decades, natural fibers have received attention of scientists and researchers due to their ecofriendly characteristics that qualify them as potential reinforcement in polymer composites in place of synthetic fibers. In this study, an experimental investigation has been conducted to evaluate the effect of orientation of fibers on mechanical properties of a newly developed bio-composite in which date palm fronds (DPF) are embedded as fibers in low-density polyethylene (LDPE) matrix. Three bio-composite sheets with orientations of $0^{\circ}, 45^{\circ}$ and $90^{\circ}$, respectively have been fabricated after the date palm fronds were chemically treated. The fabricated composite specimens are tested under tensile load using Universal Testing Machine (UTM) in accordance with the ASTM D-638 standard. Then, a comparison of the experimental results against analytical results is made to examine the accuracy and agreement between the two. An inconsistency in moduli, as was discovered, is attributed to the adhesion quality between the fibers and surrounding matrix. Output results help to assess the applicability of such class of bio-composites in real-life applications. The results of tensile strength, Young's modulus, and elongation at break revealed that date palm fronds can be used as reinforcement material in polymer-based composites for low strength applications.
\end{abstract}

Keywords: Bio-composites; Date palm fronds (DPF); Low density polyethylene (LDPE); Tensile strength.

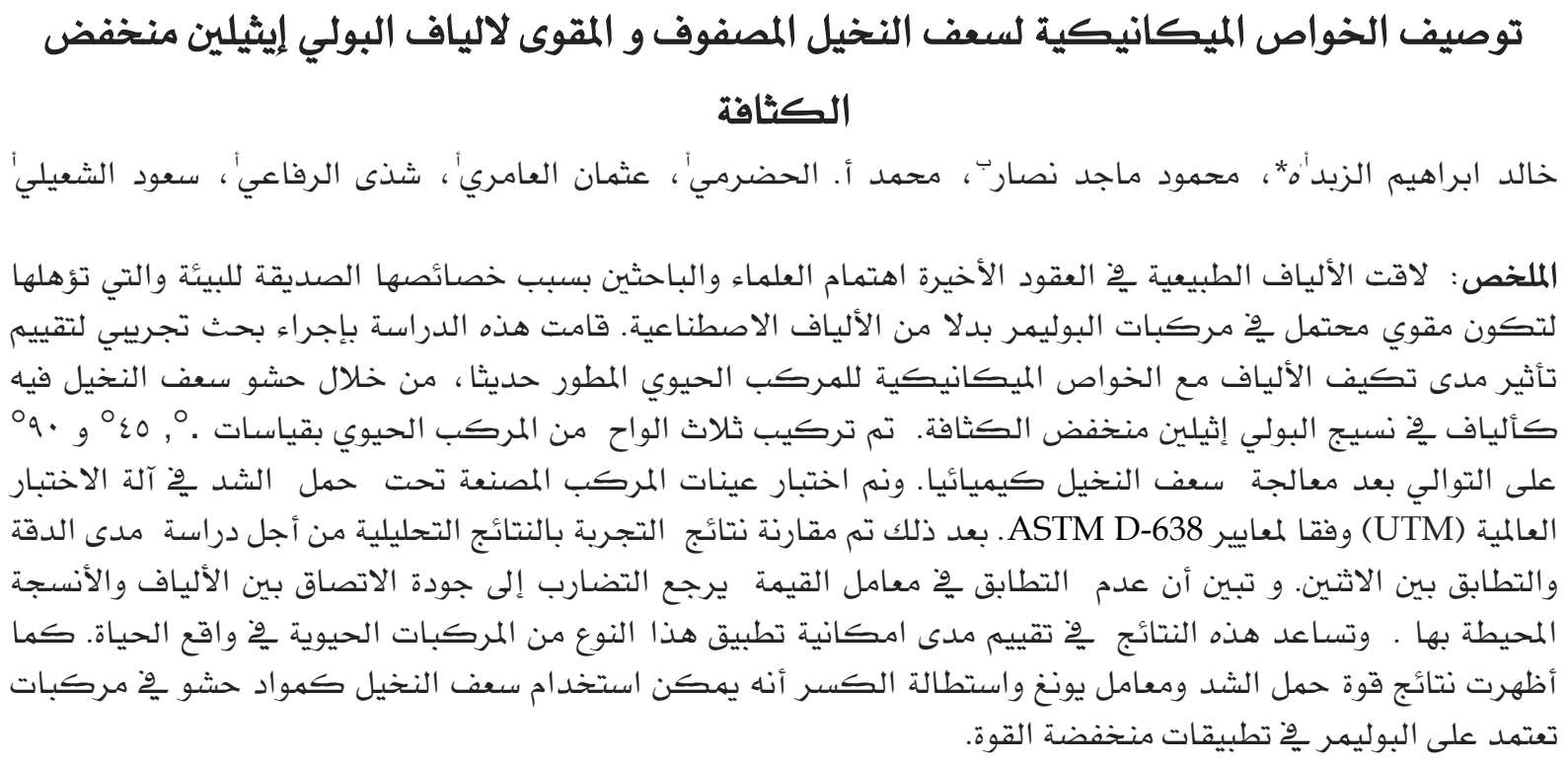




\section{Introduction}

The development of advanced renewable materials to replace the non-renewable and petroleum-based products has aroused the interest of researchers in the last few decades. Although natural fiber reinforced composites have been successfully used in various noncritical products, there is still a need to develop similar materials to broaden their industrial applications. Two constituents are processed and mixed together; natural fiber and hosting matrix, which can be either non-biodegradable or biodegradable based resin. The mechanical properties of composite materials are dependent on the properties of the two constituent phases. Fibers typically have low density, moderate specific strength and modulus, but are often very brittle. Generally, fiber distribution, concentration, and orientation are the main factors that influence the overall properties of the fabricated fiber reinforced composites (Askeland et al. 2009; Callister et al. 2007). Besides, the quality of the interface between the dispersed phases and surrounding matrix is a highly critical factor in determining the local and nonlocal behavior of a composite. Composite materials can be classified into three main types: particle-reinforced, fiber-reinforced, and structural composites. Fibers used as reinforcement make improvements in strength, stiffness, or high-temperature performance in case of metals and polymers material, and improve toughness to ceramics matrix. Currently, about 40,000 composite products are in use for an array of applications in diverse sectors of the industry around the world (Gohil and Shaikh 2010).

Date palm (Phoenix dactylifera L) is one of the oldest cultivated and most valuable fruit trees due to its ritual significance in human societies, health benefits, productive capacity in harsh semi-arid and arid environments. It is also known for the range of subsistence produced from its fruits, fronds, date seeds and other parts of the tree. Date palm plantations worldwide are estimated to have over 150 million trees (Al-Khayri et al. 2015). From each individual tree, 10 to 15 branches are cut down. Thus, on average, $35 \mathrm{~kg}$ of palm residues are obtained per tree. However, the bulk of the material is discarded as waste. Therefore, efficient utilization of this natural resource in fabricating natural fiber composite would have a positive impact on environment and could improve the economic status of rural areas (Kocak and Mistik 2015; Mohanty et al. 2014; Wazzan 2006). Overall, application of the DPF as reinforcement or filler in polymers is feasible, especially in case of annual pruning wastes, noting an abundance of available biomass of this type (Sbiai et al. 2010).

Natural fibers need to be chemically treated before mixing with the matrix. Chemical treatment of fiber helps in removing sticking dirt and improving its physical and chemical characteristics. AlMaadeed et al. (2013) and Shalwan et al. (2016) reported that the use of high $\mathrm{NaOH}$ concentration can cause deterioration in the fiber strength. Also, Alawar et al. (2009) concluded that hydrochloric acid treatment resulted in deterioration in its mechanical properties. In contrast, some results revealed that $6 \%$ concentration of $\mathrm{NaOH}$ is the optimum solution for treating date palm fiber to maintain high interfacial adhesion and strength with epoxy matrix (Alsaeed et al. 2013). Scanning electron microscopy of the composite specimens fracture surfaces indicates that the Maleic Anhydride Grafted Polypropylene (MAPP) and the treated fibers improved the interfacial interaction between the fiber and the matrix (Eslami-Farsani 2014). Based on the findings, it can be concluded that its physical and mechanical properties are not directly related to increased treatment conditions (Taha et al. 2007). The potential use of extracted date palm tree fiber has been investigated based on different aspects and methods (Al-Kaabi et al. 2005a, 2005b; AlRawahi et al. 2015; Kocak and Mistik 2015; Mohanty et al. 2014; Taha et al. 2007; Wazzan 2006). In general, date palm fibers can be extracted from the stem mesh, midribs, bark and leaves or fronds. Also, the particulate or powder can be produced by milling the date palm fruit seeds. Studies have shown that date palm fibers provide a viable alternative for exploitation in composite material fabrication and they can serve as a replacement for glass fiber, thus solving associated environmental problems.

Polymer matrix in natural fiber composites is divided into two main categories; bio-based and 
petroleum based. LDPE is a petroleum thermoplastic matrix widely used in packaging applications due to its chemical and corrosion resistance, light weight, good impact resistance, high stiffness and good process ability. However, the usage of LDPE, as a polymer matrix for reinforced composites, contributes to a serious environmental problem due to LDPE non-biodegradable properties. Also, LDPE is soft, flexible and inert, thus resists reacting with any other elements. Additionally, it possesses a low static charge, so it does not attract dust and dirt. Hence, it has a huge potential in fabrication of polymer based composites (Al-Nasir 2013; Fahim et al. 2012; Rahman et al. 2012; Sarifuddin and Ismail 2013). An enhancement in the mechanical properties of the developed biocomposites compared to the virgin LDPE has been observed (Fahim et al. 2012; Nur et al. 2010; Rahman et al. 2012). Sarifuddin and Ismail (2013) stated that the optimum tensile strength was obtained when $10 \mathrm{wt}$ \% of kenaf fiber loaded into the LDPE. In the case of Cannabis/LDPE, it has been found that the best fibers ratio is $5 \mathrm{wt}$.\% to improve the mechanical properties of the developed bio-composites (AlNasir 2013). Moreover, lower elongation of break compared to pure LDPE occurs. In another study conducted by Prasad et al. (2016), the potential use of Banana fiber in LDPE matrix was explored. It showed that a composite with composition of $25 \mathrm{wt}$ \% banana fiber is the optimal rate on the basis of biodegradability and mechanical properties.

In this study, alkali treated aligned date palm fronds are used as reinforcing fibers in lowdensity polyethylene bio-composites. Mechanical properties (modulus of elasticity, tensile strength, and strain at break) were determined via experimental testing at different fiber orientations $\left(0^{\circ}, 45^{\circ}\right.$, and $\left.90^{\circ}\right)$ at ambient temperature. In addition, analytical calculations of mechanical properties based on micromechanics are presented.

\section{Methodology}

\subsection{Composite Fabrication and Physical Testing}

The date palm fronds were manually extracted from Khusab palm tree of a local farm. Chemical analysis showed the detailed composition of all constituents (Table 1).

Firstly, fronds, as shown in Fig. 1 (a), were dried under the sun for a month, and cleaned to remove any contaminants. The extracted fronds were cut into $1250 \mathrm{~mm}$ in length. A secondhand treatment was applied using tap water as a preliminary step of the cleaning process. In order to improve morphology structure of fibers, alkali treatment using $1 \mathrm{wt} . \%$ of $\mathrm{NaOH}$ for 2 hours (Alawar et al. 2009; Taha et al. 2007) was applied. Then, $20 \mathrm{wt} . \%$ volume of fibers was aligned based on the specified direction in the mold $(200 \mathrm{~mm} \times 200 \mathrm{~mm} \times 5 \mathrm{~mm})$ using a hand lay-up method. Care was taken to achieve a uniform distribution of fibers while being layered in the LDPE matrix. Secondly, an electrical oven was used to mix the composite constituents at $300^{\circ} \mathrm{C}$ (AlMaadeed et al. 2013) until the matrix fully encapsulated the fibers as shown in Fig.1(b). Sheets were manually pressed under $25 \mathrm{~kg}$ load for 15 minutes to eliminate any porosity or void formation and maintain a uniform thickness as specified. Lastly, the composite sheets were pressed manually again for a day prior to cutting. Then, specimens were cut according to the ASTM D 638 using $\mathrm{CNC}$ machine in order to characterize their mechanical properties as shown in Fig. 2. The prepared specimens were tested using Universal Testing Machine (UTM) at a fixed cross head speed of $5 \mathrm{~mm} / \mathrm{min}$, at room temperature $23^{\circ} \mathrm{C}$ and humidity $50 \%$. For each direction, three samples were tested at a fixed gage length of $57 \mathrm{~mm}$ and average response value was recorded.

\subsection{Analytical Modeling}

A connection with the classical micromechanics may be established here. Our experimental testing

Table 1. Chemical composition of DPL fiber (Mohanty et al. 2013).

\begin{tabular}{cc}
\hline Constitutes & Percentage (\%) \\
\hline Cellulose & 54.75 \\
Lignin & 15.3 \\
Hemi-Cellulose & 20.00 \\
Pectin & 1.2 \\
Moisture & 6.5 \\
Ash & 1.75 \\
Wax & 0.50 \\
\hline
\end{tabular}




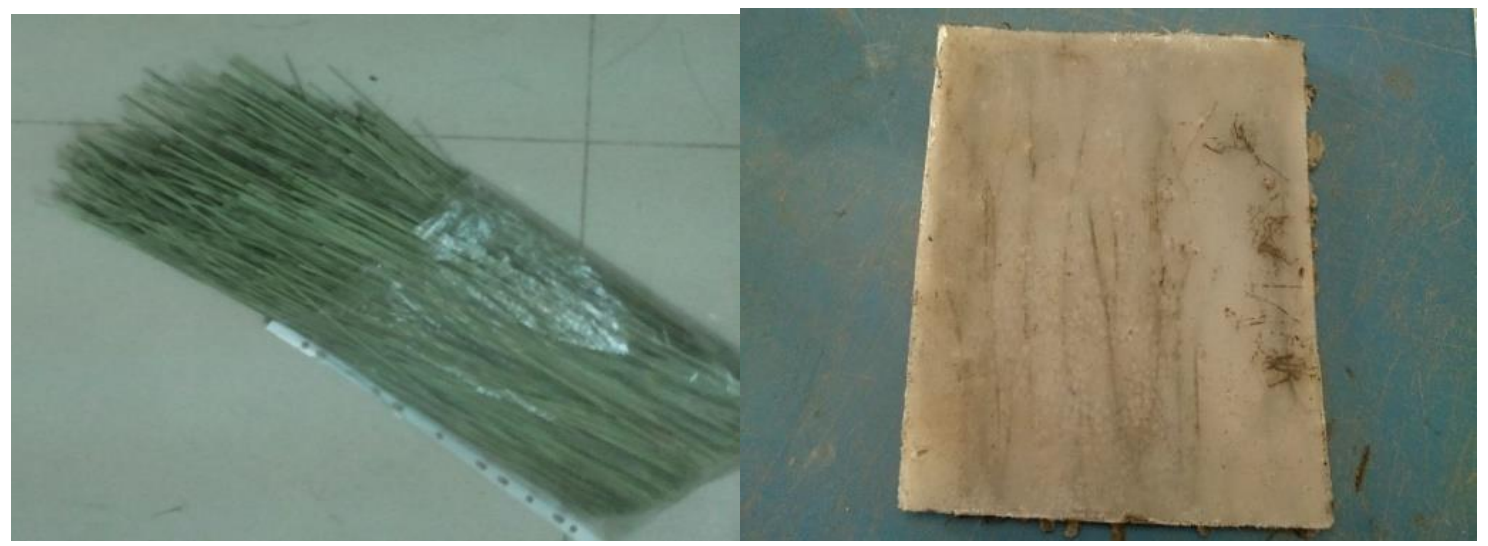

(a)

(b)

Figure 1. Manually extracted date palm fronds fibers; (a) raw, and (b) encapsulated.

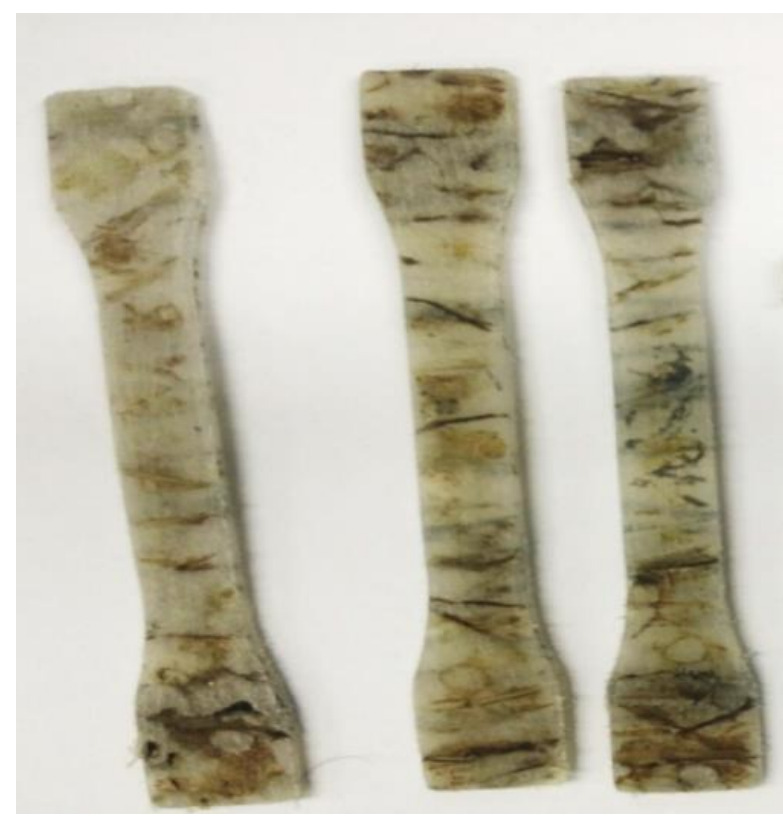

(a)

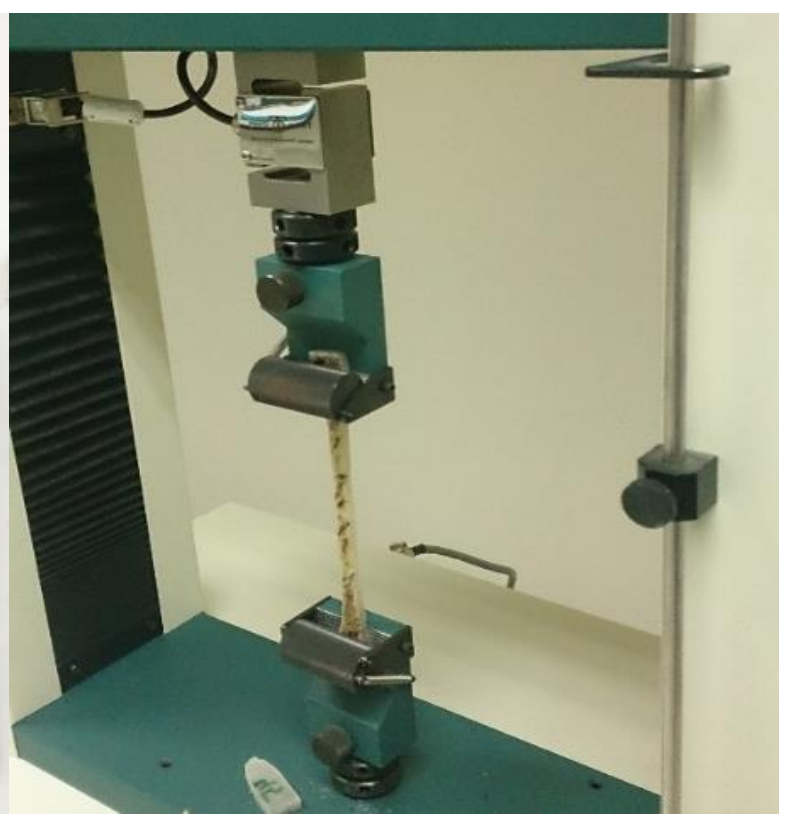

(b)

Figure 2. Tensile testing procedure $\left(\theta=90^{\circ}\right)$; (a) specimen, and (b) testing setup.

results can be compared with Voigt (rule of mixture) and Reuss bounds. For instance, Voigt bound as given by Eqn. (1), assumes a constant strain and therefore gives upper bound on effective elastic modulus of a composite $\left(E^{c}\right)$.

$$
\left(E_{u}^{c}\right)^{V}=V_{f} E^{f}+V_{m} E^{m}
$$

While Reuss bound assumes a constant stress and gives lower bound on effective elastic modulus as given in Eqn. (2).

$$
\left(E_{l}^{c}\right)^{R}=\frac{V_{f}}{E_{f}}+\frac{V_{m}}{E_{m}}
$$

Where $E_{f}, E_{m}$ are the Young's moduli of fiber and matrix, respectively and $V_{f}$ and $V_{m}$ are the volume fractions of fiber and matrix, respectively. However, it is well known that the Hashin-Strikman bounds (H-S) (Hashim 1963) give more accurate and rigorous values as compared to those of Voigt and Reuss bounds. 
Such bounds are given in Eqns. (3) \& (4) for isotropic elastic modulus of elasticity.

$$
\begin{gathered}
\left(E_{u}^{c}\right)^{H-S}=E_{f}+\frac{V_{m}}{\frac{1}{\left(E_{m}-E_{f}\right)}+\frac{V_{f}}{2 E_{f}}} \\
\left(E_{l}^{c}\right)^{H-S}=E_{m}+\frac{V_{f}}{\frac{1}{\left(E_{f}-E_{m}\right)}+\frac{V_{m}}{2 E_{m}}}
\end{gathered}
$$

Where $\left(E_{u}^{c}\right)^{H-S}$ and $\left(E_{1}^{c}\right)^{H-S}$ are the upper and lower $\mathrm{H}-\mathrm{S}$ bounds on effective elastic modulus of a composite. It is important to mention that all these bounds assume prefect bonding between fibers and surrounding matrix.

\section{Results and Discussion}

The mechanical properties of both fiber and matrix used in this study are given in Table 2 .

One observation on the tensile properties of both fiber (frond) and matrix (LDPE) is a noticeable mismatch between the two ingredi-

Table 2. Mechanical properties of fibers and matrix used.

\begin{tabular}{ccccc}
\hline & $\begin{array}{c}\text { Tensile Strength } \\
\mathbf{( M P a )}\end{array}$ & $\begin{array}{c}\text { Tensile Strain } \\
\mathbf{( \% )}\end{array}$ & $\begin{array}{c}\text { Young's Modulus } \\
\mathbf{( G P a )}\end{array}$ & Specific Gravity \\
\hline Khusab frond & 19 & 4.7 & 5.4 & 1.17 \\
Neat LDPE & 9.6 & 100 & 0.4 & 1.08 \\
\hline
\end{tabular}

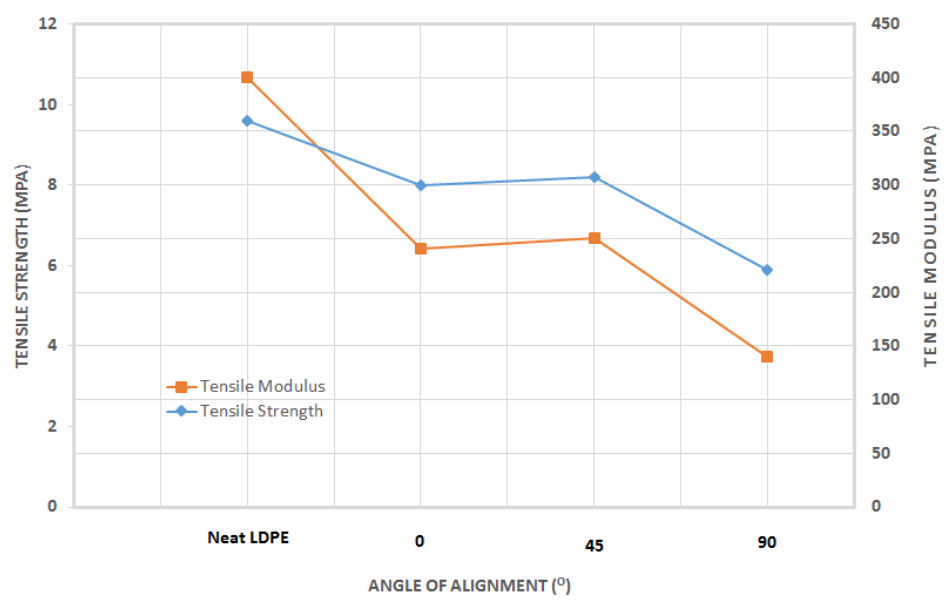

Figure 3. Tensile strength (left) and Tensile Modulus (right) of the tested bio-composites sheets.

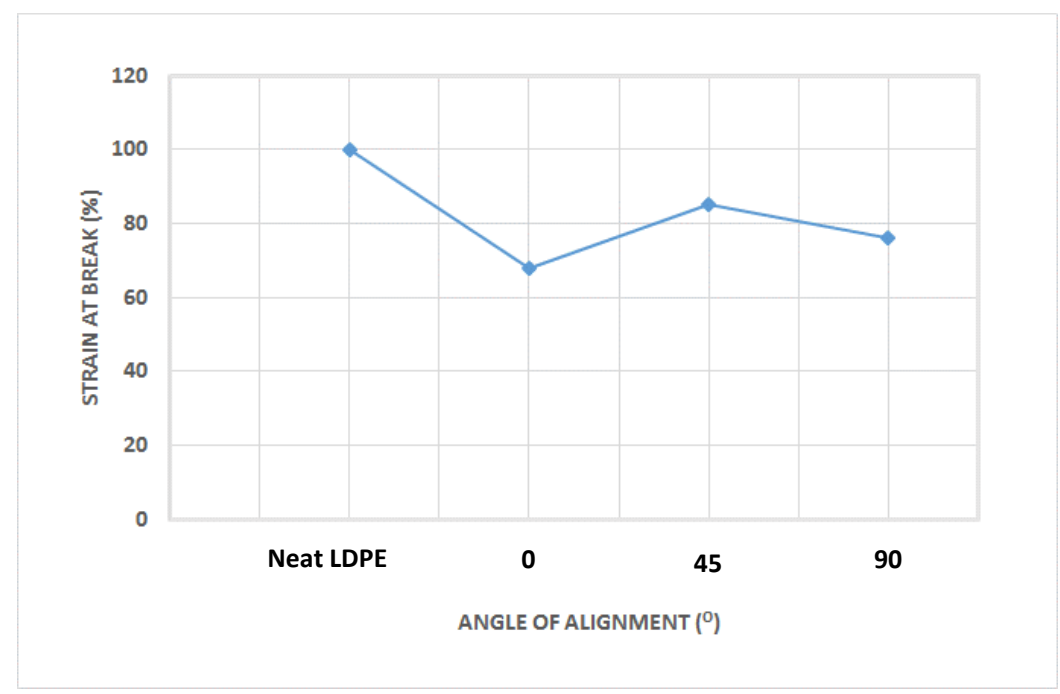

Figure 4. Strain at break of the tested bio-composites sheets. 
-ents can be detected. This may affect the interfacial properties of the interface region and can lead to a degradation in tensile properties of the composites.

For all the tested composite specimens, mechanical properties were degraded in relation to those of neat LDPE. For tensile strength, around 14\% drop was observed in case of $\theta=0^{\circ}$ (Fig. 3), which is considered to be reasonable as there were several limitations in the fabrication process that contributed to a poor adhesion between fiber and surrounding matrix. At $\theta=45^{\circ}$, a slight stronger composite was obtained. As expected, the weakest composite occurred at $\theta=90^{\circ}$. Young's modulus follows a similar behavior (Fig. 3). A drop of $15 \%$ in strain at failure was obtained for composite at $\theta=0^{\mathrm{o}}$. It is almost an equal strain at failure for both specimens at $\theta=0^{\circ}$ and $\theta=$ 45 (Fig. 4). Recently, Alzebdeh et al. (2016) studied the mechanical properties of chopped date palm fronds reinforced LDPE. At $20 \%$ volume of date palm fronds, a tensile strength in the range of 5.81 to $7.2 \mathrm{MPa}$ was obtained. Therefore, continuous date palm frond reinforcement composites showed slightly higher strength.

The recorded stress-strain curves under uniaxial tensile loading are shown in Fig. 5. As reflected in the approximate linear region of these curves, Young's moduli are similar in both cases $\theta=0^{\circ}$ and $\theta=45^{\circ}$ with the weakest value at $\theta=90^{\circ}$. Yield for the first two cases occurred at strain equal to 0.3 while for the third case, it occurred at strain around 0.6. Ultimate tensile strength of $8.4 \mathrm{MPa}$ was achieved at $\theta=45^{\circ}$ with higher toughness.

Analytical modeling results in the whole range of volume fraction of fibers are depicted in Fig. 6. Again, it is worthwhile to emphasize that these bounds assume perfect bonding between fiber and hosting matrix. With admitted limitations on hand-lay-up method of fabrication, it is clear that this assumption is not well satisfied here.

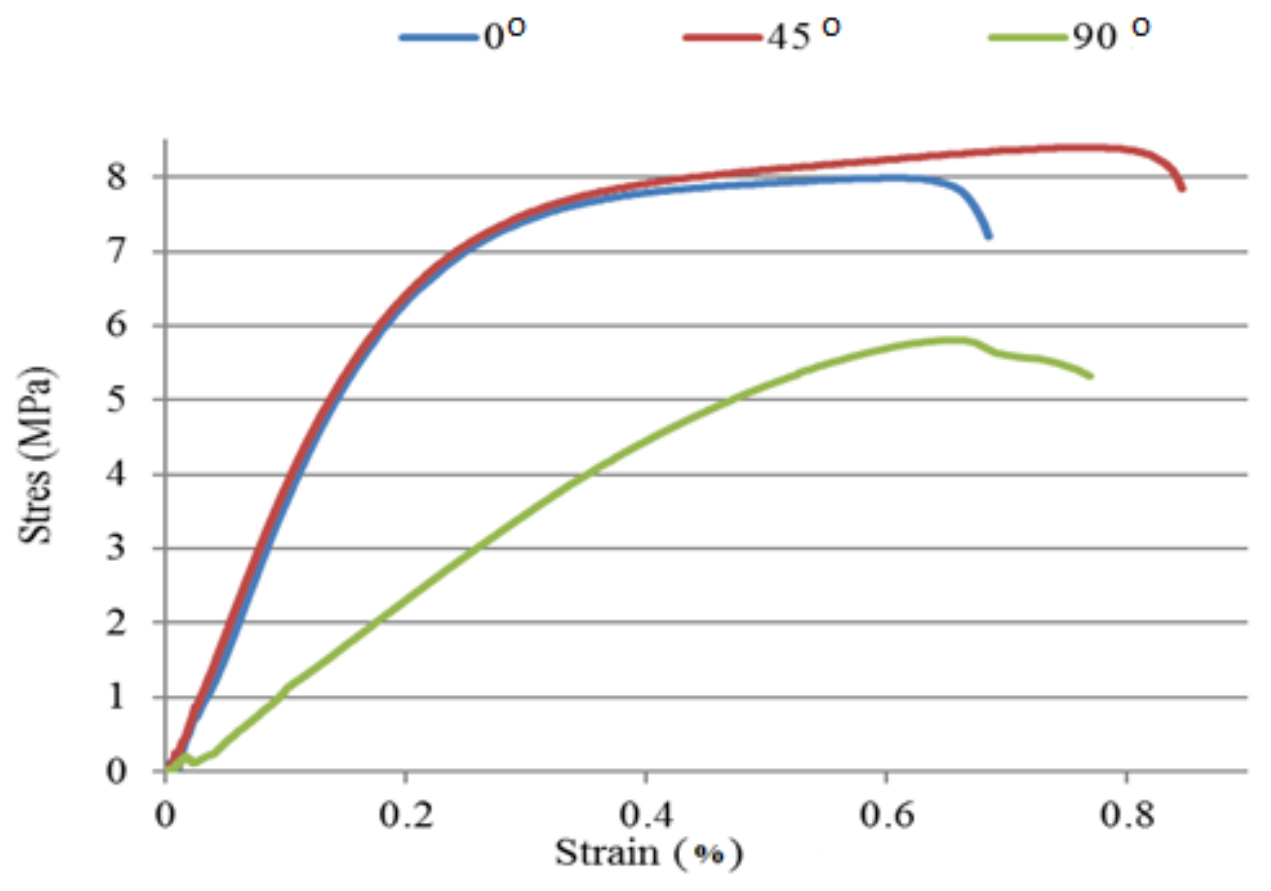

Figure 5. Stress-Strain curves in tension of tested specimens. 


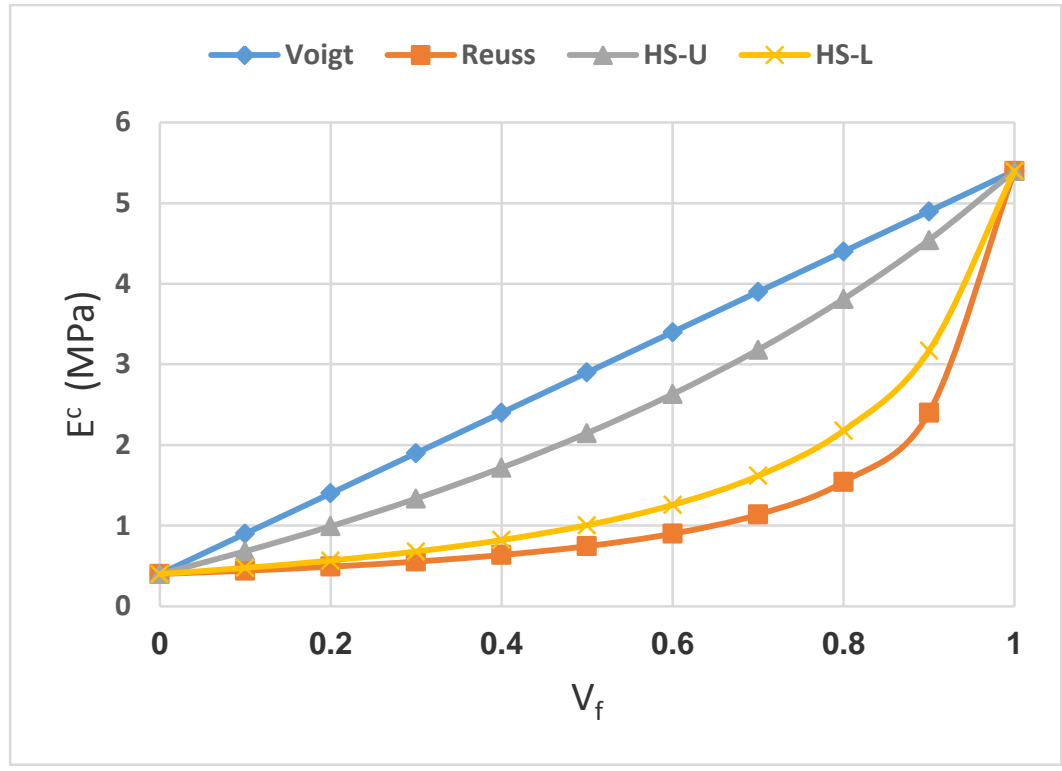

Figure 6. Bounds on effective Young's modulus.

Table 3. Young's modulus (GPa) as obtained experimentally and analytically.

\begin{tabular}{ccccc}
\hline Experiment & Voigt & Reuss & $\begin{array}{c}\text { H-S } \\
\text { (upper) }\end{array}$ & $\begin{array}{c}\text { H-S } \\
\text { (lower) }\end{array}$ \\
\hline 0.25 & 1.4 & 0.49 & 0.99 & 0.56 \\
\hline
\end{tabular}

At $20 \%$ volume fraction and $0^{\circ}$ orientation, Young's modulus of $0.25 \mathrm{GPa}$ is obtained, which is less than the corresponding analytical values (Table 3).

A better controlled fabrication process that ensures a strong adhesion between fibers and hosting matrix will result in a closer matching of experimental values of Young's modulus to those estimated analytically.

\section{Conclusion}

The increasing awareness toward the biodegradable natural fibers, as an alternative to synthetic fibers, has generated an interest to develop eco-friendly polymer composite materials. In this study, three sheets of LDPE were fabricated using hand lay-up method in which continuous palm tree fronds were aligned as fibers. Based on experimental testing for mechanical properties, a few observations can be highlighted:

- In general, mechanical properties have been degraded with a drop of $16 \%$ in tensile strength, $37 \%$ in tensile modulus and $15 \%$ in strain at failure.
- This degradation in mechanical properties is attributed to the poor adhesion between fibers and matrix.

- $45^{\circ}$ orientation of fiber resulted in higher tensile strength.

- A mismatch between the experimental and analytical results occurred due to lack of perfect bond between fiber and matrix.

Regardless of such drop in mechanical properties of the new developed DPF/LDPE composites, preliminary results indicate that using date palm fronds as fillers in plastics and other types of polymers is promising as these biodegradable fronds are priceless, have abundant source, which is considered as waste. Finally, it can be concluded that date palm fronds fibers can be used as "reinforcing" material for low strength applications with cost effectiveness and environmental awareness.

\section{Conflict of Interest}

The authors declare no conflicts of interest. 


\section{Funding}

No funding was received for this research.

\section{References}

Al-Kaabi K, Al-Khanbashi A, Hammami A (2005a), Date palm fibers as polymeric matrix reinforcement: DPF/polyester composite properties. Polymer Composites, 26(5): 604-613.

Al-Kaabi K, Al-Khanbashi A, Hammami A (2005b), natural fiber reinforced composites from date fibers. The European Society for Composite Materials: 1-8.

Al-Khayri JM, Jain SM, Johnson DV (2015), Date palm genetic resources and utilization. date palm genetic resources and utilization: Volume 1: Africa and the Americas (Vol. 1): 318.

Al-Nasir EA (2013), Study of the mechanical properties of low density polyethylene composites with cannabis ( Hemp fibers ). Journal of Basrah Researches (Sciences), 39(3):15-22.

Alawar A, Hamed A, Al-Kaabi K (2009), Characterization of treated date palm tree fiber as composite reinforcement. Composites Part B: Engineering, 40(7): 601-606.

AlMaadeed MA, Kahraman R, Noorunnisa KP, Al-Maadeed S (2013), Characterization of Untreated and Treated Male and Female Date Palm Leaves. Materials and Design 43: 526-531.

AlRawahi HH, Alzebdeh KI, Nassar MMA (2015), Statistical modeling of mechanical properties of chopped date palm frond reinforced polypropylene composites. In Proceeding from the 8th International Conference on Materials Science and Engineering , Al-Sharjah, UAE 74-77.

Alsaeed T, Yousif BF, Ku H (2013), The potential of using date palm fibers as reinforcement for polymeric composites. Materials and Design, 43:177-184.

Alzebdeh K, Nassar, M, AlRawahi N , Al-Hinai $\mathrm{H}$ (2016), Characterization of mechanical properties of date palm fronds reinforced low density polyethylene (LDPE). In Proceedings of the ASME 2016 International Mechanical Engineering Congress and Exposition, Phoenix, Arizona, USA 1-10.

Askeland DR, Fulay PP, Bhattacharya DK (2013), Essentials of Materials Science and Engineering, $3^{\text {nd }}$ ed. CL Engineering.
Callister W, Rethwisch D, Wiley J (2009), Materials Science And Engineering: An Introduction. $8^{\text {th }}$ ed., John Wiley and Sons

Eslami-Farsani R (2015), Effect of Fiber Treatment on the mechanical properties of date palm fiber reinforced PP/EPDM composites. Advanced Composite Materials, 24: $27-40$.

Fahim IS, Elhaggar SM, Elayat H (2012), Experimental investigation of natural fiber reinforced polymers. Materials Sciences and Applications 3: 59-66.

Gohil PP, Shaikh AA (2010), Experimental investigation and micro mechanics assessment for longitudinal elastic modulus in unidirectional cotton-polyester composites. International Journal of Engineering and Technology 2(2): 111-117.

Hashim Z (1963), Approach to the theory of the elastic behaviour of multiphase materials. Journal of the Mechanics and Physics of Solids 11(42): 127-140.

Kocak D, Mistik SI (2015), the use of palm leaf fibers as reinforcements in composites. In book: Biofiber Reinforcements in Composite Materials 273-281

Mohanty J, Das S, Das H, Mahanta T, Ghadei S (2014), Solid particle erosion of date palm leaf fiber reinforced polyvinyl alcohol composites. Advances in Tribology, 2014:1-8.

Mohanty JR, Das SN, Das HC, Swain SK (2013), Effective mechanical properties of polyvinylalcohol biocomposites with reinforcement of date palm leaf fibers. Polymer Composites 34(6): 1548-569.

Nur HP, Hossain MA, Mollah MM (2010), Preparation of polymer composites using natural fiber and their physico- mechanical properties. Bangladesh Journal of Scientific and Industrial Research 45(2): 117-122.

Prasad N, Agarwal VK, Sinha S (2016), Banana fiber reinforced low-density polyethylene composites: effect of chemical treatment and compatibilizer addition. Iranian Polymer Journal 25: 229-241.

Rahman WA, Sudin SNA, Din SN (2012), Physical and mechanical properties of pandanus amaryllifolius fiber reinforced low density polyethylene composite for packaging application. SHUSER 2012 - 2012 IEEE Symposium on Humanities, Science and Engineering Research (9002): 345-349.

Sarifuddin N, Ismail H (2013), Comparative study on the effect of bentonite or feldspar filled low-density polyethylene / thermoplastic sago starch / kenaf core fiber 
composites. Journal of Physical Science 8(2): 4238-4257.

Sbiai A, Maazouz A, Fleury E, Souterneau H, Kaddami H (2010), Short date palm tree fibers / polyepoxy composites prepared using rtm process: Effect Of Tempo Mediated Oxydation Of The Fibers. BioResources 5(2): 672-689.

Shalwan A, Oraby S, Alaskari A (2016), Mathematical modelling of the interfacial adhesion of date palm/epoxy. Journal of Materials Science Research 5(3): 29.
Taha I, Steuernagel L, Ziegmann G (2007), Optimization of the alkali treatment process of date palm fibers for polymeric composites. Composite Interfaces 14(7-9): 669-684.

Wazzan A A (2006), The Effect of Surface Treatment on the strength and adhesion characteristics of phoenix dactylifera-l(date palm) fibers. International Journal of Polymeric Materials 55(7): 485-499. 